\section{EMBRYAIDDLE \\ Aeronautical University}

SCHOLARLY COMMONS

\section{International Journal of Aviation,} Aeronautics, and Aerospace

7-21-2018

\title{
Measuring Public Utilization Perception Potential of Unmanned Aircraft Systems
}

Julius Keller

Purdue University, keller64@purdue.edu

Daniel Kwasi Adjekum

University of North Dakota, kadjekum@yahoo.com

Bortiorkor Nii Tsui Alabi

Purdue University, balabi@purdue.edu

Brian Kozak

Purdue University, kozak@purdue.edu

Follow this and additional works at: https://commons.erau.edu/ijaaa

Part of the American Politics Commons, Models and Methods Commons, Science and Technology Studies Commons, and the Social Statistics Commons

\section{Scholarly Commons Citation}

Keller, J., Adjekum, D. K., Alabi, B. N., \& Kozak, B. (2018). Measuring Public Utilization Perception Potential of Unmanned Aircraft Systems. International Journal of Aviation, Aeronautics, and Aerospace, 5(3).

https://doi.org/10.15394/ijaaa.2018.1243

This Article is brought to you for free and open access by the Journals at Scholarly Commons. It has been accepted for inclusion in International Journal of Aviation, Aeronautics, and Aerospace by an authorized administrator of Scholarly Commons. For more information, please contact commons@erau.edu. 


\section{Measuring Public Utilization Perception Potential of Unmanned Aircraft Systems}

Cover Page Footnote

Grateful to the general public for their responses and enthusiasm which made this project successful. 
Unmanned Aircraft Systems (UAS), also known as Unmanned Aerial Vehicles (UAV) or drones, continue to receive overwhelming attention in areas of aviation and advanced technological engineering (Tetrault, 2016). UAS have evolved from a research curiosity to mainstream practical applications. UAS can range in weight from a few grams to 15 tons (Clothier et al., 2015). The Federal Aviation Administration (FAA) expects recreational and commercial UAS to increase from 2.5 million to 7 million in 2020 (FAA, 2016a).

According to the Teal Group Corporation's (2015) forecast, UAS production for civilian use will increase from current revenues of $\$ 4$ billion to $\$ 14$ billion, over the next decade. Military spending on UAS is expected to add $\$ 30$ billion during the same period. Business Insider Intelligence's (2016) forecast significant growth in civilian UAS operations and projects $\$ 12$ billion of revenue by 2021. Furthermore, corporations such as Amazon and Google are seeking to expand commercial applications for a wide range of services (Amazon.com, 2016; Cuthbertson, 2016).

Unmanned aircraft systems can be used to execute difficult and hazardous tasks cost-effectively (Association for Unmanned Vehicle Systems International, 2016). UAS technology is currently used in operations such as security, search and rescue, monitoring (e.g., pipelines, air sampling, electrical lines), disaster management, crop management, communications, surveying, and photography/videography (National Conference of State Legislatures, 2016). Unmanned aircraft system manufacturers and software developers continue to advance UAS technological proficiencies, such as See and Avoid (SAA) capabilities, in the attempt to make UAS operations safer and to facilitate their integration into the National Air Space (NAS).

Introducing UAS into NAS is complicated because the U.S. has the busiest and most intricate airspace system in the world (FAA, 2016a). The initial implementation has not come without controversy (Elwell, 2017). Major concerns for integrating UAS into the NAS include privacy infringements, impact on national security and the economy, influence on international diplomacy and relations, risks of damage to property and people, and public perceptions to the acceptance of the technology (NCSL, 2016).

In recognition of the potential technological benefits, economic impacts, and socio-political concerns associated with UAS operations, the Federal Aviation Administration Modernization and Reform Act (Public Law 112-95, Title III, Subtitle B - Unmanned Aircraft Systems) was passed (FAA, 2012). This legislation requires a plan to integrate UAS into civilian airspace which has created a 
tremendous challenge for the FAA. The FAA manages and regulates nonrecreational UAS use through special airworthiness certificates, exemptions, and Certificates of Waiver or Authorization (COA). Operational and certification rules for small unmanned aircraft systems fall under the 14 Code of Federal Regulations (CFR) Part 107. Part 107 focuses on non-recreational operations of UAS weighing less than 55 pounds or $25 \mathrm{~kg}$ and the certification required for their use (FAA, 2016).

Excerpts of the new rule which are pertinent to public perception, include operational limitations, certification and responsibilities, aircraft requirements and model aircraft. Regarding operational limitations, the FAA specifies that the UAS model should fly within the operator's Visual Line-of-Sight (VLOS), at a maximum ground speed of $100 \mathrm{mph}$ (87 knots), and a maximum altitude of 400 feet above ground level (AGL) (Subpart B - §107.51). The rule prohibits the carriage of hazardous materials and permits external load only if it is attached securely and does not impair flight characteristics (Subpart B - §107.23).

About remote pilot in command certification and responsibilities, the rule requires that the operator (of age no less than 16 years) possess a remote pilot airman certificate with a small UAS rating. Other aspects of the new rule addressesaircraft restrictions, for example, the UAS must be registered and prohibits UAS operators from endangering the safety of NAS (Subpart C - §107.61; 107.63; $107.65 ; 107.67 ; 107.73)$.

The new rule does not explicitly deal with privacy issues in the use of drones, and the FAA does not regulate how UAS gather data on people or property. However, the FAA strongly encourages all UAS pilots to check local and state laws before gathering information through remote sensing technology or photography (FAA, 2016).

Public perceptions often influence rules, regulations, and technological advancement. With the current proliferation and expected demand, it is essential to research instruments continue to be developed and validated. This study aims to validate a research instrument Public Utilization Perception Potential (PUPP) which can be used to effectively gauge current public perceptions of UAS and be used longitudinally. The study also aims at providing empirical data for the utilization of UAS commercial flight services by the public and to evaluate the strength of relationships between the factors that underlie PUPP. Researchers of the current study utilized previous studies to guide the development of the PUPP. 


\section{Research Questions}

1. What are the factors that measure Public Utilization Perception Potential (PUPP) of UAS?

2. What are the strengths of the relationship between the factors that measure Public Utilization Perception Potential (PUPP) of UAS?

3. What is the validity of a measurement model that assesses the relationships between the exogenous variables Utilization Trust, Safety Risk-Benefits, Functional Knowledge, Operational Integration Support and the endogenous variable Public Utilization Perception Potential $(P U P P)$ of UAS?

4. What are the differences in the mean scores of respondents on factors that measure Public Utilization Perception Potential (PUPP) of UAS among the demographic variables gender, educational background, type of traveler and location of primary residence?

\section{Literature Review}

A study on public support for UAS conducted by Monmouth University (2012) sampled 1,708 American adults estimated that 80\% supported the use of unmanned aircraft to help in search and rescue missions with a margin of error of $+2.4 \%$. The study suggested two-thirds of Americans supported the use of UAS to track criminals and to protect the U.S. border (AUVSI, 2016). According to The Institute for Homeland Security Solutions (2013), 57\% of the respondents supported the use of UAS for any application, $88 \%$ supported the use of UAS for search and rescue, $63 \%$ in fighting crime, $67 \%$ for homeland security, and $61 \%$ for commercial applications.

These observations suggested a wide-spread public acceptance of the use of UAS. Nevertheless, support for the use of UAS was a low $43 \%$ in general everyday use, citing public concerns such as the management of the transition to the domestic airspace, safety issues, and the ability of government to regulate its use (Institute for Homeland Security Solutions, 2013). Figure 1 shows the areas of public support regarding UAS deployment.

A review of extant research on public and stakeholder perceptions and acceptance of drones demonstrated that most respondents support or opposition to UAS is conditional and complex with determining factors being risks, application type, environment, and benefits of UAS operations and applications. Generally, respondents in research studies indicated support for the use of UAS for public service, land management, and security. There have been other research efforts 
that addressed adverse effects of UAS (such as privacy) or perceptions regarding such effects (Mehta et al., 2017). However, there are relatively very few research studies that used large samples to investigate respondent knowledge about UAS, trust, safety risk-benefits and operational integration.

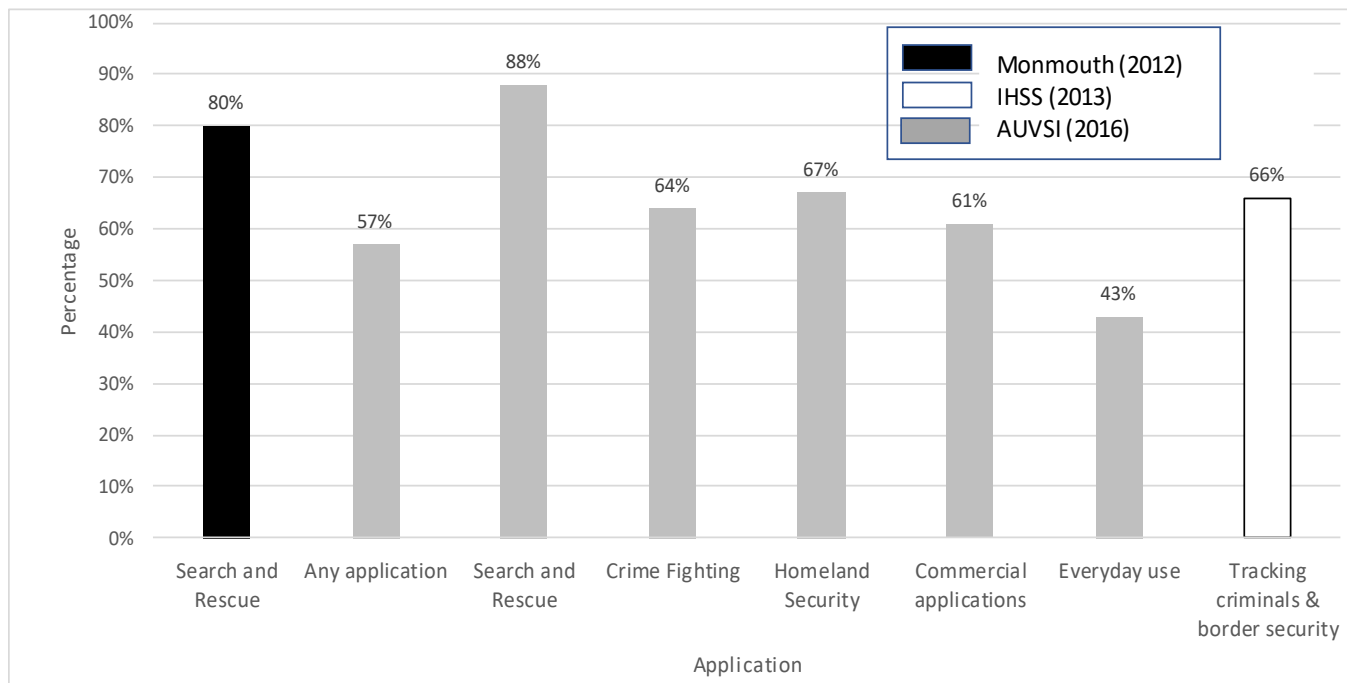

Figure 1. Areas of public support regarding UAS deployment.

Knowledge has been defined in various ways as, human faculty resulting from interpreted information; understanding that germinates from a combination of data, information, experience, and individual interpretation (Harman, 1990). Knowledge often rests on inference and exposure; highlighting the importance of information. Knowledge is a driver of cognitive perception of a phenomenon (Shi, Siegrist, \& Arvai, 2016). Therefore, knowledge in the context of this paper investigates participants' familiarity with UAS and technological applications. This UAS functional knowledge assessment includes beliefs, attitudes, available information, and perceived concerns of respondents on UAS operations.

McKnight and Chervany (1996) define trust as, "the extent to which one party is willing to depend on the other party in each situation with a feeling of relative security, even though negative consequences are possible." Trust has always been a central issue in philosophical and ethical approaches to evaluating the technology. Major trust concerns of technology range from issues of safety and reliability to analyses of risk and development of precautionary standards (Kiran \& Verbeek, 2010). 
Trust represents confidence despite possible adverse outcomes. Using technology, therefore, implies trusting oneself to technology (Kiran \& Verbeek, 2010). Trusting technology involves factors such as reliability, validity, utility, robustness, and false-alarm (Hoffman, Johnson, Bradshaw, \& Underbrink, 2013). In this regard, intentions of trust for UAS utilization can vary from "reliance" on UAS multipurpose applications to "suspicion", in the form of precautionary approaches in ethics; and the outright "distrust" in terms of public unacceptability for UAS operations (Hoffman, Johnson, Bradshaw, \& Underbrink, 2013).

Per Scheer et al. (2010), the word "risk" has different connotations in everyday use, as it often refers to the likelihood of an adverse effect resulting from an event or an activity, rather than an opportunity for desired outcomes. Kates, Hohenemser, and Kasperson (1985), define risks like the possibility that human actions lead to consequences that affect something of value to humans. Scientists generally deem the term risk to denote the probability distribution of adverse effects (Renn, 2008).

Given these definitions and the understanding of UAS as a relatively new technology, the current paper adopts the description of (technological) risk as "the likelihood of physical, social, or financial harm because of a technology" as postulated by Renn and Benighaus (2012). Evaluating the consequences of UAS operations also entails the consideration of its potential threats (hazards) such as potential harm to nature, humans, capital and human-made facilities (Scheer et al., 2010).

The mental and psychological mechanisms by which individuals use to discern risk are internalized by social and cultural cognition continually reinforced by the media, peer influences, and other communication forms (Renn, 2008). The media, a principal channel of information to the public, regulators, and policymakers, plays an essential role in shaping society's response to technology (Kasperson, Kates, \& Hohenemser, 1985).

In sum, the literature review showed that public perception of UAS deployment could be placed in at least four categories: functional knowledge, utilization trust, safety risk-benefit, and operational integration. Therefore, it is essential to use these categories as a basis for identifying and assessing such public perceptions. In addressing a gap in the literature, this paper hypothesizes that the public's perceptions of UAS can be adequately assessed based on the functional knowledge, utilization trust, operational integration support and safety riskbenefits. 


\section{Method}

This paper proposes a theoretical model to assess the strength of the relationship between the public perception of UAS utilization (the endogenous variable) and the factors that affect such utilization (the exogenous variable) and to calibrate the model using structural equation modeling (SEM) techniques. Figure 2 presents the proposed measurement model of public utilization perception potential (PUPP).

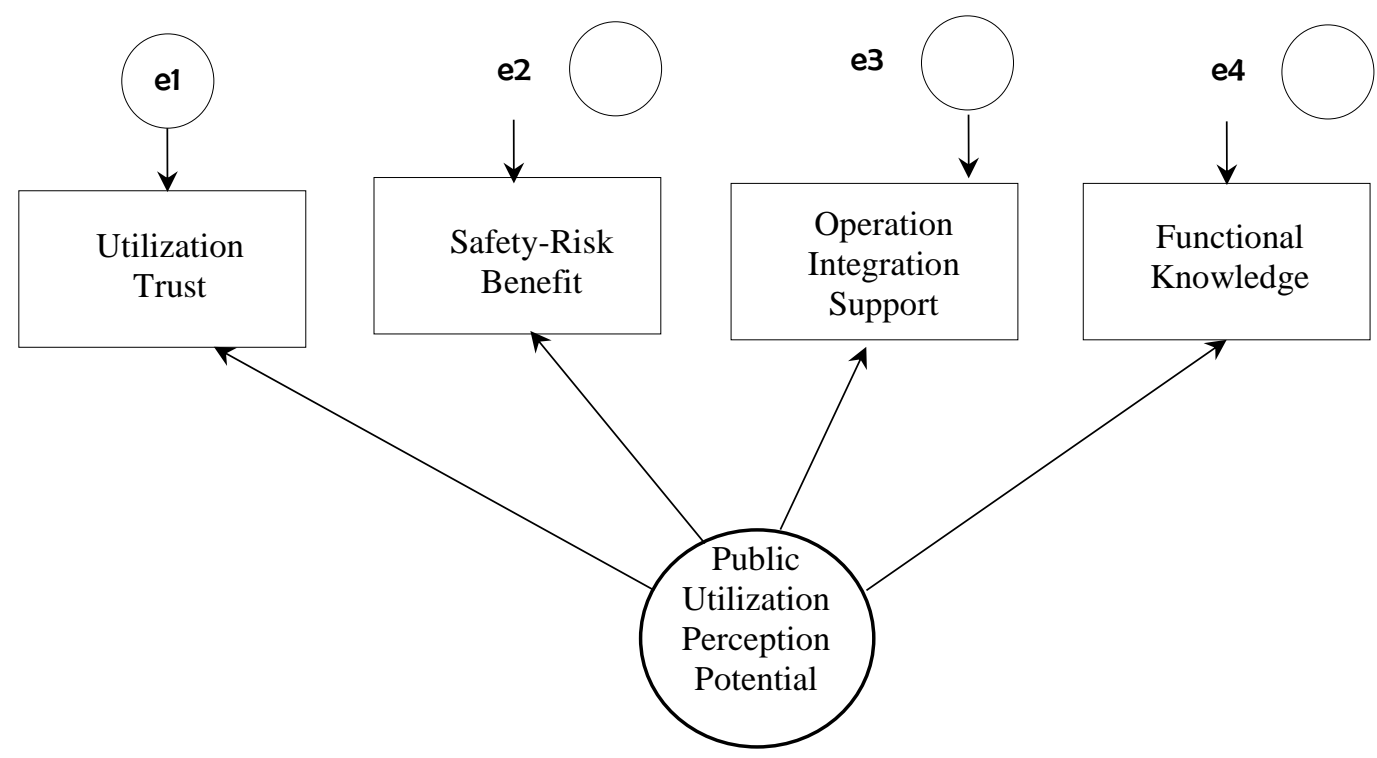

Figure 2. Proposed Measurement Model of Public Utilization Perception Potential (PUPP).

\section{Research Instrument and Procedures}

A mixed-methods survey approach was adopted for the study. The research instrument used in data collection consisted of six sections. The first section of the instrument was the consent and demographic section. Respondents were asked their age, gender, education level, income level, the frequency of travel, the primary purpose of travel, region of residence in the U.S., and residential category (rural, suburban, or urban). The second section pertained to knowledge and participants were asked to respond a Yes or No style question items, select from a list of options, the source of knowledge, and True or False items pertinent to UAS operations.

Third, was the trust utilization section that assessed the perceptions of respondents using a 5-point Likert-type scale survey items (Strongly Disagree Strongly Agree). It measured the trust that these respondents have in various UAS 
operations and specific operators (government, commercial, recreational/public). Moreover, respondents were also asked to rate their level of trust and alacrity to utilize UAS airline passenger services.

The fourth section of the research instrument pertained to safety riskbenefits of UAS. These items asked respondents to rate their perceptions of risks and probability of midair collisions between manned and unmanned aircraft in addition to sharing airspace. The fifth section inquired about respondents' support for the various use of UAS. Respondents also had the opportunity to provide written responses to qualitatively give depth to their responses. These were analyzed and coded for emergent themes and was used for a different analysis.

After the preliminary research instrument was designed, beta-testing was conducted to improve the external validity and reliability. Four subject-matter experts (SME) in the UAS field provided feedback, and multiple revisions were made to improve comprehensibility, simplicity, technical verbiage and flow of the survey items. The final survey instrument consisted of 35 items and comment boxes for qualitative feedback. Details of the survey item can be accessed via a provided hyperlink in the Appendix.

After obtaining Institutional Review Board (IRB) approval, the PUPP was distributed using an online survey tool, Amazon Mechanical Turk $®$. The survey tool service connects researchers to the public for completion of research surveys. A convenient sampling method targeted those who were at least 18 years of age. Respondents were required to consent to the terms of the IRB protocol and were paid after completion of the survey. The data collection period was between February 2017 to March 2017.

\section{Results}

\section{Quantitative Data Analysis and Validation}

The quantitative survey data was imported from the Qualtrics $®$ data collection software into the SPSS ® software and analyzed. Significant statistical values were set at the 0.05 alpha levels (2-tailed) for most of the analyses unless otherwise specified. The responses from the items in the survey were reduced using a factor analysis approach, and the resulting items that loaded strongly on factors were tested for content validity and reliability of the scale.

Descriptive and inferential analyses were conducted using IBM SPSS 23® and IBM AMOS Graphics 23® software (IBM SPSS, 2015). The descriptive 
analysis included mean, standard deviation, standard error of the mean, normality test (kurtosis and skewness) and physical inspections of the resultant normal distribution curves. The inferential analysis included bivariate correlations, $t$-test of mean, analysis of variances (ANOVA), and measurement model validation using SEM.

In the validation of the proposed measurement model to establish the relationship between the exogenous variables and the endogenous variable PUPP, some omnibus tests for assessing how well a model matches an observed data (goodness-of-fit measure to determine overall model fit) were used. The Root Mean Square Error of Approximation (RMSEA) was primarily used to determine model fit. Generally, a recommended value of 0.05 or less indicates a close fit of the measurement model about the degrees of freedom (Brown, 2006).

Another test statistic for the goodness of fit is the Comparative Fit Index (CFI) that evaluates the fit of a user-specified solution about a more restricted, nested baseline model, in which the covariance among all input indicators are fixed to zero or no relationship among variables is posited (Brown, 2006). The fit index CFI ranges from 0 , for a poor fit, to 1 for a good fit. Finally, the Tucker-Lewis Index (TLI) is another index for a comparative fit that "includes a penalty function for adding freely estimated parameters" (Brown, 2006). According to Brown (2006), the TLI may be interpreted similarly as CFI but can have a value outside of the range of 0 to 1 .

$\mathrm{Hu}$ and Bentler (1999) provided rules of thumb for deciding which statistics to report and choosing cut-off values for declaring significance. When the Root Mean Square Error of Approximation (RMSEA) values are 0.05 or below, and CFI and TLI are 0.95 or higher, the model may have a reasonably good fit. The chisquare $\left(\chi^{2}\right)$ is another test statistic but is sensitive to sample size, and it becomes difficult to retain the null hypothesis as the number of cases increases (Kline, 2005). The $\chi^{2}$ test may also be invalid when distributional assumptions are violated, leading to the rejection of good models or the retention of bad ones (Steven, 2002; Brown, 2006).

\section{Demographic Data}

The details of the demography for the study were important to establish how it affects the perceptions on UAS. Differences in perceptions based on demographic variables also help in formulating policies that will be pragmatic and sensitive to changes. Males made up 51\% $(n=539)$ of respondents while $46 \%(n=488)$ were women and $.01 \%(\mathrm{n}=13)$ preferred not to mention their gender. 
Regarding the highest level of education attained by respondents, $27.9 \%$ were high school graduates or General Education (G.E.D), 18.6\% had a two-year College (associate degree), 39.4\% had a bachelor's degree, and $11.3 \%$ had a graduate, professional degree, or higher. $2.9 \%$ had other qualifications or preferred not to say. Figure 3 presents the age distribution of the respondents. The figure indicates that the survey targeted a wide range of age groups with the dominant groups falling between $23-47$ years.

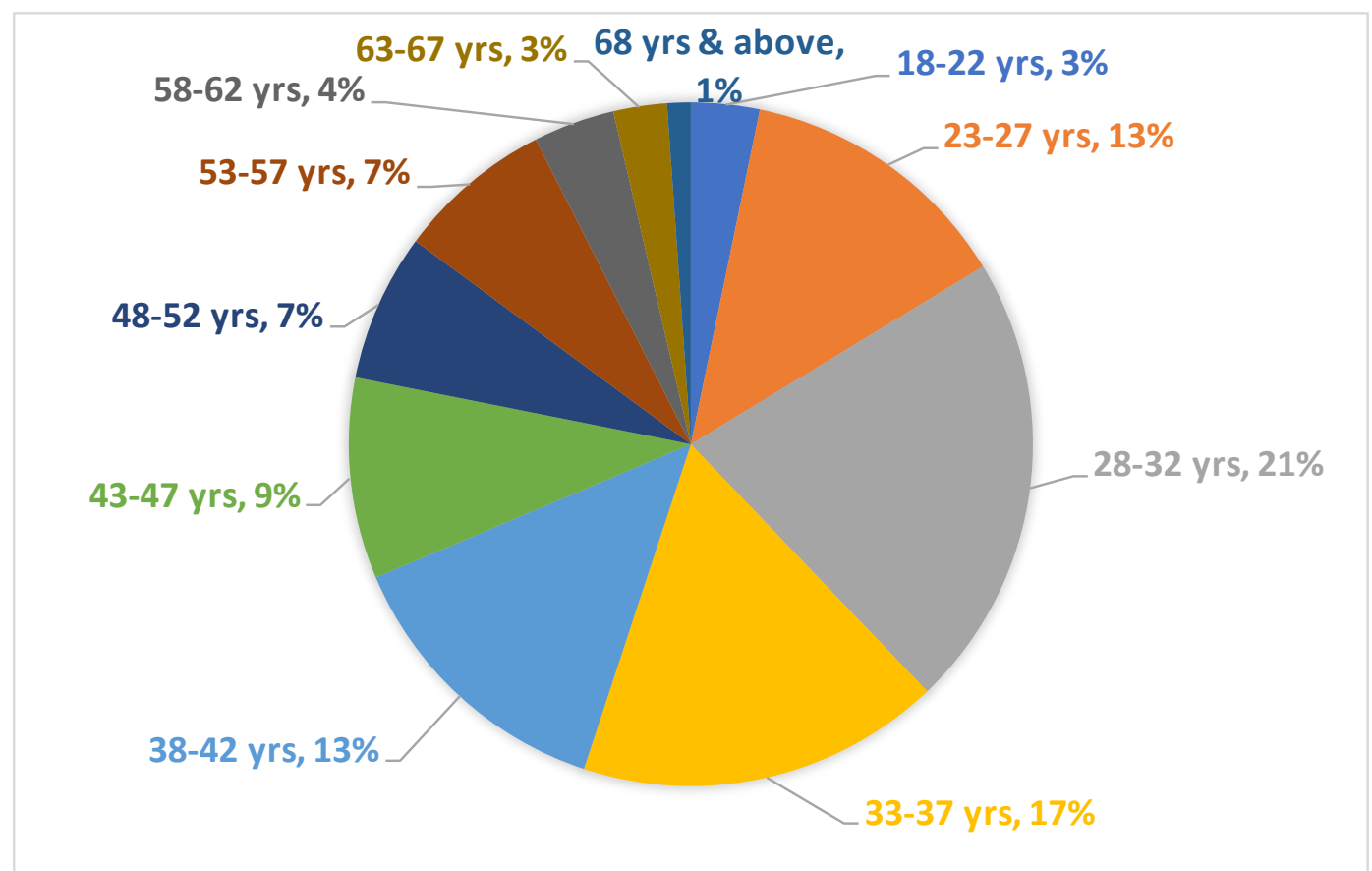

Figure 3. Age distribution of respondents.

Respondents were asked whether they had heard of Unmanned Aircraft Systems or drones, before participating in the survey. Ninety percent answered affirmatively while $6.3 \%$ said they had not; $3.5 \%$ did not answer. Regarding knowledge about Unmanned Aircraft Systems or drones, $4.8 \%$ said they were knowledgeable, $27.4 \%$ stated that they were somewhat knowledgeable, $64.5 \%$ indicated no knowledge, and 3.3\% did not answer. Regarding current ownership, of an Unmanned Aircraft System or drone, $4.9 \%$ stated that they currently own one; 91.8\% do not own one, and 3.3\% did not answer. Twenty percent (20\%) of the respondents indicated that they would like to own a drone in future; $22 \%$ stated that they had no intention owning a drone in future, and $49.6 \%$ were unsure. 
The survey respondents indicated a rather wide range of UAS information sources, with the dominant sources being electronic and print media (85.5\%). Also, very small percentages of respondents indicated that they had their information from other sources [military experience $(0.6 \%)$, governmental sources $(0.8 \%)$, fiction novels $(0.4 \%)$, personal experience $(2.6 \%)$, aviation associations $(1.2 \%)$, college or vocational programs $(0.3 \%)]$. Figure 4 shows the distribution of knowledge of respondents about UAS-related terms.

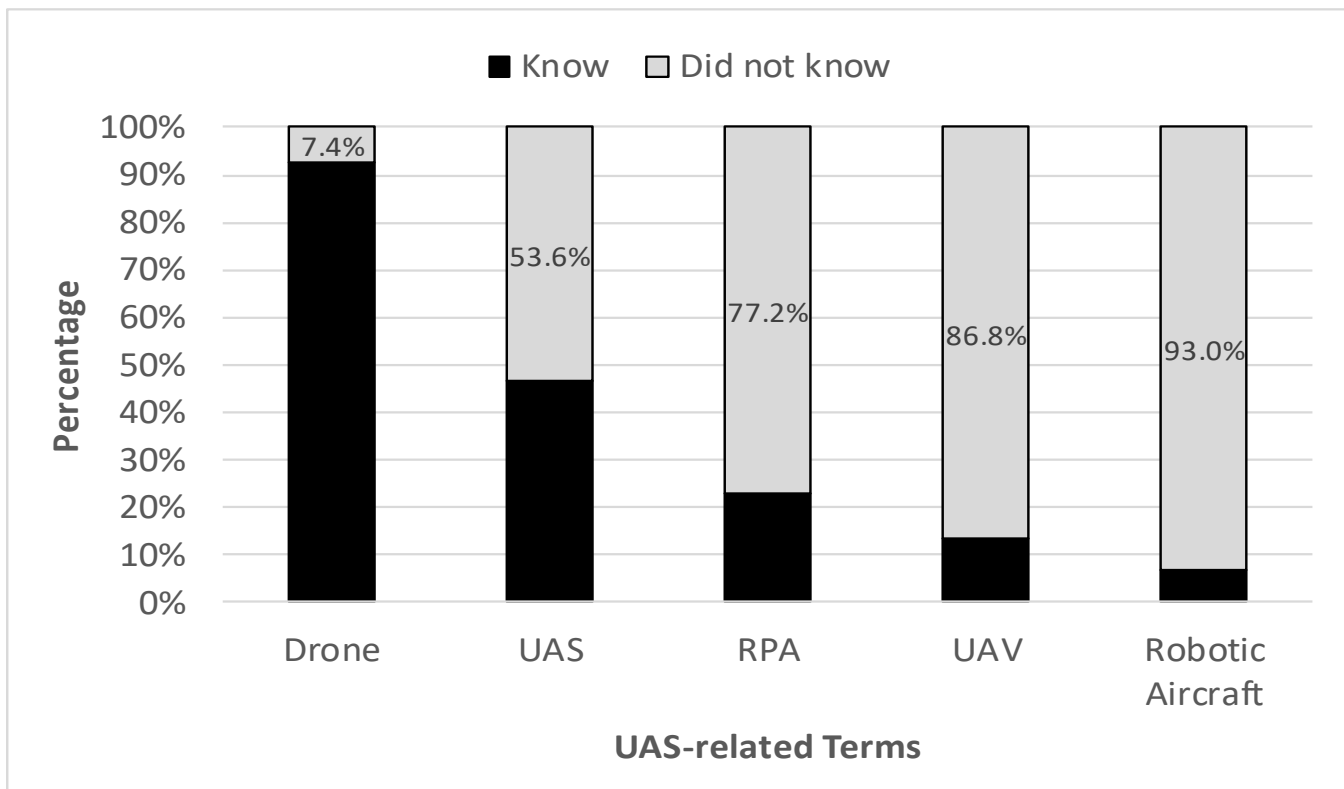

Figure 4. Familiarity of respondents with UAS-related terms.

\section{Addressing Research Questions}

Question One - Factors that measure Public Utilization Perception Potential of UAS. A principal axis factoring (PAF) was conducted on 35 items of the PUPP questionnaire using a varimax rotation. Absolute coefficient values for the extractions after rotation were limited to 0.05 and above to ensure the quality of items that will load on factors and to ensure parsimony. Overall, 23 items showed strong loading above the initial criteria. However, three items namely Trust3_1, Trust3_2, Trust3_3 loaded separately under various factors and were deleted.

Overall, 20 items were extracted from the preliminary 35 items in the questionnaire. The Kaiser-Meyer-Olkin measure verified the sampling adequacy for the analysis, $\mathrm{KMO}=0.89$ which was above the acceptable limit of 0.5 (Field, 
2013). An initial analysis was run to obtain the eigenvalues for each factor in the data. Four factors had eigenvalues over the Kaiser's criterion of 1 and in combination explained $59.66 \%$ of the variance. The scree plot showed ambiguous inflections that would justify retaining either three or four factors. Four factors were retained because of the large sample size and the convergence of the scree plot and Kaiser's criterion on this value.

The items that clustered on the same factor suggest that factor 1 represents safety-risk benefits of UAS technology (Safety-Risk benefit), factor 2 represents trust in UAS application and readiness to utilize passenger airline services (Utilization Trust), factor 3 represents support for UAS integration into the national airspace system (Operational Integration Support) and factor 4 the level of knowledge on UAS (Functional Knowledge). The safety risk-benefit, trust and support scales of the PUPP all had high reliabilities; all Cronbach's $\alpha>0.80$. However, the knowledge scale had relatively low reliability, Cronbach's $\alpha=0.68$ when compared to recommendations by both Stevens (2002) and Fields (2009) for an alpha value $(\alpha>0.70)$.

The descriptive statistics on the items in each scale were conducted. The results were determined to be consistent with the assumptions of normally distributed data and were confirmed using histograms and normality plot. The summary of the factor analysis, eigenvalues, proportion of variance explained, and reliability are shown in Table 1 . Table 2 shows the descriptive statistics of the four scales that underlies the PUPP. The scree plot can be found in the Appendix.

Question Two - The strengths of the relationship between the factors that measure Public Utilization Perception Potential of UAS. A Pearson's bivariate correlation of the four scales that underlie the PUPP was conducted to test the strengths of the linear relationship between these underlying scales. The rationale was to answer one of the research questions and to establish possible linear relationships that are essential in building the conceptual model for validating the PUPP. Table 3 presents the correlations between these factors.

The findings from the analysis show that the strongest statistically significant positive correlation exists between the scales safety-risk benefits and trust, $r(989)=0.53, p<0.001$ (2-tailed). The correlation between safety-risk benefits and support was positively statistically significant, even though the strength of the relationship was relatively weak, $\mathrm{r}(989)=0.12, p<0.001$ (2-tailed). The correlation between Trust and knowledge was negatively statistically significant. However, the strength of relation was weak, $\mathrm{r}(999)=0.09, p<0.001$ (2-tailed). There existed a negatively statistically significant relationship between 
safety-risk benefits and knowledge, and the strength of relation was relatively small, $\mathrm{r}(999)=0.07, p<0.005$ (2-tailed).

\section{Table 1}

Summary of exploratory factor analysis results for the PUPP questionnaire $(N=1040)$

\begin{tabular}{|c|c|c|c|c|c|}
\hline Factor Items & Variable Name & $\begin{array}{l}\text { Safety } \\
\text { Risk- } \\
\text { Benefits }\end{array}$ & Trust & $\begin{array}{l}\text { Operational } \\
\text { Support }\end{array}$ & Knowledge \\
\hline $\begin{array}{l}\text { Most Unmanned Aircraft Systems currently in use are } \\
\text { capable of operating completely autonomously, without } \\
\text { any human controller. }\end{array}$ & DK16_1 & & & & 0.534 \\
\hline $\begin{array}{l}\text { Special approval from the Federal Aviation } \\
\text { Administration is required to legally operate Unmanned } \\
\text { Aircraft Systems in the United States. }\end{array}$ & DK16_2 & & & & 0.582 \\
\hline $\begin{array}{l}\text { Unmanned Aircraft Systems can range in cost from a } \\
\text { few dollars to millions of dollars. }\end{array}$ & DK16_3 & & & & 0.634 \\
\hline $\begin{array}{l}\text { Would you fly in an Unmanned Aircraft Systems type } \\
\text { passenger airliner for business travel? }\end{array}$ & Trust1_1 & & 0.903 & & \\
\hline $\begin{array}{l}\text { Would you fly in an Unmanned Aircraft Systems type } \\
\text { passenger airliner for leisure travel? }\end{array}$ & Trust1_2 & & 0.913 & & \\
\hline $\begin{array}{l}\text { Would you fly in an Unmanned Aircraft Systems type } \\
\text { passenger airliner for international travel? }\end{array}$ & Trust1_3 & & 0.853 & & \\
\hline $\begin{array}{l}\text { Would you fly in an Unmanned Aircraft Systems type } \\
\text { passenger airliner for domestic travel? }\end{array}$ & Trust1_4 & & 0.917 & & \\
\hline $\begin{array}{l}\text { The Unmanned Aircraft Systems technology is safe? } \\
\text { (Does not endanger human life and properties) }\end{array}$ & Safety_B 2_1 & 0.718 & & & \\
\hline $\begin{array}{l}\text { The Unmanned Aircraft Systems technology is risky to } \\
\text { the public. }\end{array}$ & Safety_B2_2Rev & 0.693 & & & \\
\hline $\begin{array}{l}\text { The Unmanned Aircraft Systems technology is } \\
\text { beneficial to my family and me. }\end{array}$ & Safety_B2_3 & 0.542 & & & \\
\hline $\begin{array}{l}\text { The Unmanned Aircraft Systems technology is } \\
\text { beneficial to society. }\end{array}$ & Safety_B2_4 & 0.625 & & & \\
\hline $\begin{array}{l}\text { The Unmanned Aircraft Systems technology is } \\
\text { threatening to my family and me. }\end{array}$ & Safety_B2_5Rev & 0.751 & & & \\
\hline
\end{tabular}




\section{Table 1- Cont.}

\begin{tabular}{|c|c|c|c|c|c|}
\hline Factor Items & Variable Name & $\begin{array}{l}\text { Safety Ris } \\
\text { Benefits }\end{array}$ & -Trust & $\begin{array}{l}\text { Operational } \\
\text { Support }\end{array}$ & Knowledge \\
\hline $\begin{array}{l}\text { The Unmanned Aircraft Systems technology is } \\
\text { threatening to society. } \\
\text { (Public Security) }\end{array}$ & Safety_B2_6 Rev & 0.782 & & & \\
\hline $\begin{array}{l}\text { The Unmanned Aircraft Systems technology is as safe } \\
\text { as other technologies used in transportation. }\end{array}$ & Safety_B2_7 & 0.648 & & & \\
\hline $\begin{array}{l}\text { How much would the following factors affect your } \\
\text { support to Unmanned Aircraft Systems (UAS)? - The } \\
\text { application for which the UAS is used. }\end{array}$ & Support1_1 & & & 0.682 & \\
\hline $\begin{array}{l}\text { How much would the following factors affect your } \\
\text { support to Unmanned Aircraft Systems (UAS)? - The } \\
\text { environment in which the UAS is used. }\end{array}$ & Support1_2 & & & 0.738 & \\
\hline $\begin{array}{l}\text { How much would the following factors affect your } \\
\text { support to Unmanned Aircraft Systems (UAS)? - The } \\
\text { benefits that the UAS provides. }\end{array}$ & Support1_3 & & & 0.678 & \\
\hline $\begin{array}{l}\text { How much would the following factors affect your } \\
\text { support to Unmanned Aircraft Systems (UAS)? - The } \\
\text { costs incurred as a result of UAS use. }\end{array}$ & Support1_4 & & & 0.519 & \\
\hline $\begin{array}{l}\text { How much would the following factors affect your } \\
\text { support to Unmanned Aircraft Systems (UAS)? - The } \\
\text { risks associated with operating UAS. }\end{array}$ & Support1_5 & & & 0.745 & \\
\hline $\begin{array}{l}\text { How much would the following factors affect your } \\
\text { support to Unmanned Aircraft Systems (UAS)? - The } \\
\text { characteristics of the UAS. }\end{array}$ & Support1_6 & & & 0.643 & \\
\hline Eigenvalues & & 6.81 & 3.39 & 1.92 & 1.70 \\
\hline$\%$ Variance & & 29.61 & 14.31 & 8.35 & 7.39 \\
\hline Cronbach Alpha $(\alpha)$ & & 0.85 & 0.97 & 0.83 & 0.68 \\
\hline
\end{tabular}

a. Note: Only factor loadings above .50 are shown.

b. Rev. means item was reverse-coded. 
Table 2

Descriptive Statistics of 4 Scales underlying PUPP

\begin{tabular}{lllll}
\hline Scale & Mean & Standard Deviation & Number of items & N \\
& & & & \\
\hline Trust & 2.19 & 1.132 & 4 & 999 \\
Safety Risk-Benefits & 3.02 & 0.844 & 7 & 990 \\
Support & 3.62 & 0.816 & 6 & 990 \\
Knowledge & 1.89 & 0.649 & 3 & 1002
\end{tabular}

Table 3

Bivariate Correlation of Scales that measure PUPP

\begin{tabular}{llllll}
\hline & & Trust & $\begin{array}{l}\text { Safety Risk- } \\
\text { Benefits }\end{array}$ & Support & Knowledge \\
\hline Trust & Pearson Correlation & 1 & & & \\
& $\mathrm{~N}$ & 999 & & & \\
Safety-Risk & Pearson Correlation & $\mathbf{0 . 5 2 6}$ * $^{* *}$ & 1 & & \\
Benefits & $\mathrm{N}$ & 989 & 990 & & \\
& Pearson Correlation & 0.047 & $\mathbf{0 . 1 1 9}^{* *}$ & 1 & \\
Support & $\mathrm{N}$ & 999 & 990 & 990 & \\
& Pearson Correlation & $\mathbf{- 0 . 0 8 7 ^ { * * }}$ & $\mathbf{- 0 . 0 6 5}$ & 0.014 & 1 \\
Knowledge & N & 999 & 990 & 990 & 1002
\end{tabular}

**. Correlation is significant at the 0.01 level (2-tailed).

*. Correlation is significant at the 0.05 level (2-tailed).

Question Three - The validity of a measurement model that assesses the relationships between the exogenous variables (Trust, Safety Risk-Benefits, Knowledge, Support) and the endogenous variable Public Utilization Perception Potential (PUPP) of UAS. A measurement model that assesses the relationship between the exogenous variables (Trust, Safety Risk-Benefits, Knowledge, and Support) that underlies the endogenous variable Public Utilization Potential of UAS was developed using the AMOS 24 software. The details of the final fit index $(\mathrm{CMIN}=4,442 ; \mathrm{df}=2 ; p=0.109 ; \mathrm{TLI}=0.963 ; \mathrm{CFI}=0.993$; RMSEA $=0.034)$, suggest that the measurement model was a good fit of the empirical data $(\mathrm{RMSEA} \leq 0.05)$ as suggested by $\mathrm{Hu}$ and Bentler, 1999. 
This results also validate the initial hypothesis that the observed exogenous variables Trust, Safety Risk-benefits, Knowledge, and Support were statistically significant scales that underlie the Public Utilization Perception Potential (PUPP) latent construct. The model also suggests that the exogenous variable with the most significant impact on PUPP was Safety Risk-Benefit with standardized regression weight $(\beta=0.915, p<0.005)$.

This means that for every unit change of the perception regarding safety risk-benefit of UAS, the PUPP of UAS increased by .915. The model also suggests that the exogenous variable with the minimal significant impact on PUPP was Knowledge $(\beta=-0.078, p<0.05)$. This means that for every unit change of Knowledge on UAS technology, the PUPP decreased by 0.078 .

Details of the estimates of the goodness-of-fit for the final measurement model are shown in Table 4. Details of the Regression Weights and Critical Ratios are also shown in Table 5. Figure 5 shows the Final Measurement Model of Public Utilization Perception Potential (PUPP) with standardized regression weights and unstandardized regression weights respectfully.

Table 4

Goodness-of-fit Estimate for Final Measurement Model.

\begin{tabular}{lllllllll}
\hline Model & $\begin{array}{l}\text { Chi- } \\
\text { square } \\
\left(X^{2}\right)\end{array}$ & df & $p$ & TLI & CFI & RMSEA & LO 90 & HI 90 \\
\hline $\begin{array}{l}\text { Final } \\
\text { Measurement } \\
\text { Model }\end{array}$ & 4.442 & 2 & 0.109 & 0.963 & 0.993 & 0.034 & 0.000 & 0.078 \\
\hline
\end{tabular}

Table 5

Regression Weights and Critical Ratios of Variables of the Final Measurement Model.

\begin{tabular}{lllllll} 
Exogenous & Endogenous & Estimate & S.E. & C.R. & $p$ & Estimates $(\beta)$ \\
\hline Trust & PUPP & 1.000 & & & & 0.576 \\
Safety-Risk Benefit & PUPP & 1.186 & 0.382 & 3.109 & 0.002 & 0.915 \\
Support & PUPP & 0.156 & 0.044 & 3.558 & $* * *$ & 0.125 \\
Knowledge & PUPP & -0.078 & 0.034 & -2.264 & 0.024 & -0.078 \\
\hline
\end{tabular}

Note: $* * * \mathrm{p}<0.001$ 


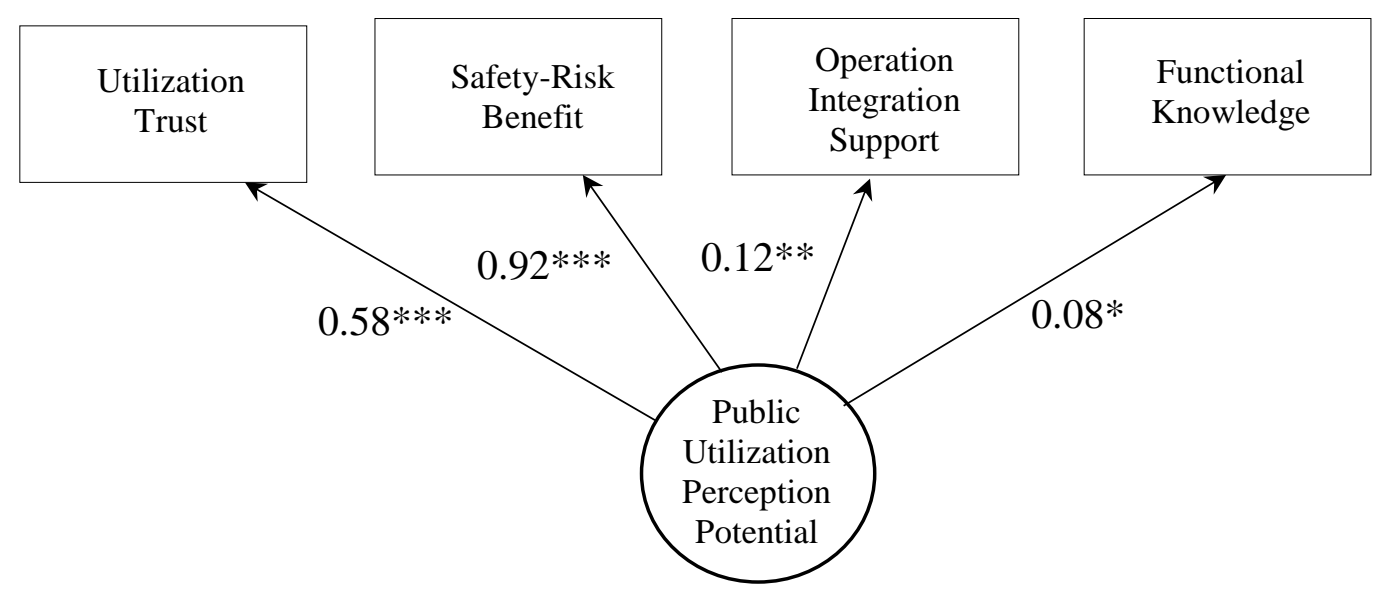

Figure 5. Final Measurement Model of Public Utilization Perception Potential (PUPP) with Standardized Regression Weights. Note: $* * * p<.001$, $* * p<.01,{ }^{*} p<.05$. (Error terms omitted).

Question Four - The differences in the factors that measure Public Utilization Perception Potential of UAS among some demographic variables (gender, educational background, type of traveler and location of primary residence).

Gender. An objective of this study was to find out if there was a difference between the mean of scores of responses to the research instrument variables Trust, Support, Safety Risk Benefits and Knowledge by gender (male and female). An independent $t$-test, which is an inferential statistical test that determines whether there is a statistically significant difference between the means in two unrelated groups, was used for the analysis (Fields, 2009).

The data was assumed normal, and the assumption of homogeneity of variance was assessed by the Levene's test, with an $F$-ratio of $F(232)=0.82, p$ > 0.05 (2T). The result indicates that the assumptions of equal variance were met; therefore, the equal variances assumed the version of the $t$-test was used. There were statistically significant differences in the mean scores on Trust for males ( $M$ $=2.44, S D=1.167)$, and females $(M=1.90, S D=1.021)$. The $t$-test value was, $t$ $(997)=7.73, p=0.001(2 \mathrm{~T})$ with $95 \% \mathrm{CI}[(-0.402)-(0.675)]$. 
There were statistically significant differences in the mean scores on SafetyRisk Benefits for males $(M=3.15, S D=0.787)$, and females $(M=2.86, S D=$ $0.878)$. The $t$-test value was, $t(998)=5.57, p=0.001$ (2T) with $95 \%$ CI $[(-0.190)$ $-(0.398)]$. There were statistically significant differences in the mean scores on Knowledge for males $(M=1.85, S D=0.635)$, and females $(M=1.93, S D=0.660)$. The $t$-test value was, $t(1000)=-1.99, p=0.050$ (2T) with 95\% CI $[(-0.162)-(-$ $0.001)]$. There was however, no significant differences in the means scores on support between the gender, $\mathrm{t}(999)=-0.639, p=0.523(\mathrm{~ns})$. Table 6 presents the descriptive statistics of the gender distribution.

Table 6

Descriptive Statistics Showing the Gender Distribution

\begin{tabular}{lllll}
\hline Variable & Gender & $\mathrm{N}$ & Mean & Std. Deviation \\
\hline \multirow{2}{*}{ Trust } & Male & 525 & 2.4438 & 1.16748 \\
& Female & 474 & 1.9051 & 1.02129 \\
Safety-Risk benefits & Male & 522 & 3.1580 & 0.78790 \\
& Female & 468 & 2.8632 & 0.87823 \\
Support & Male & 519 & 3.5999 & 0.79691 \\
& Female & 471 & 3.6331 & 0.83658 \\
Knowledge & Male & 528 & 1.8504 & 0.63568 \\
& Female & 474 & 1.9318 & 0.66085 \\
\hline
\end{tabular}

Educational Background. A one-way ANOVA was conducted to determine if there were some statistically significant differences in the mean scores of the PUPP among respondents with different educational backgrounds. There was a statistically significant effect of educational status on Knowledge on UAS based on mean scores, $F(4,1001)=3.41, p<0.01(2 \mathrm{~T})$. There were no significant findings for the other factors. To find out the groups with statistical differences, a post-hoc analysis using the Bonferroni correction in SPSS (Field, 2013) was used for the analysis.

There was a statistically significant difference between the mean scores of G.E.D holders and B.S groups with the G.E.D holders $(M=1.99, S E=0.199)$ being more knowledgeable than the B.S holders $(M=1.81, S E=0.185)$. The difference (0.184), $p=0.002$ (2-tailed) with $95 \% C I(0.043-0.325)$ had a small effect $(\omega=$ $0.1)$.

Type of Traveler. There was a statistically significant effect of type of traveler status on Trust based on mean scores, $F(3,995)=4.75, p<0.01$ (2-tailed). A post-hoc analysis using the Bonferroni correction in SPSS (Field, 2013) was used to determine specific group differences in mean scores. There was a 
statistically significant difference between the mean scores of other travelers and flight crew based on Trust and willingness to travel commercially on UAS.

The flight crew $(M=2.91, S E=0.391)$ had more trust and were more willing to travel by UAS than others $(M=1.76, S E=0.113)$. The difference ($1.150), p=0.022(2 \mathrm{~T})$ with $95 \% C I[-2.173-(-0.106)]$ had a small effect $(\omega=0.1)$. Similarly, there was statistical significance between the mean scores of other travelers and business class passengers on Trust and willingness to travel commercially on UAS. Business passengers $(M=2.36, S E=0.190)$ had more trust and were more willing to travel by UAS than others $(M=1.76, S E=0.113)$. The difference $(-0.609), p=0.009(2 \mathrm{~T})$ with $95 \% C I[-1.114-(-0.105)]$ had a small effect $(\omega=0.1)$.

Location of Residence. There was no statistically significant effect of location of residence on any of the factors underlying the PUPP based on mean scores. The results suggest that the location of residence of the respondents did not influence mean responses to Trust, Safety-Risk Benefits of UAS, Support, and Knowledge.

\section{Discussion}

The study hypothesizes that the factors Functional Knowledge, Utilization Trust, Operation Support Integration, and Safety Risk-Benefit on UAS are the essential underlying scales that measures Public Utilization Perception Potential (PUPP) of UAS. A final measurement model was developed from a conceptual measurement model that showed a good fit for the empirical data using the RMSEA index and criteria recommended by $\mathrm{Hu}$ and Bentley (1999). The final measurement model validated the initial hypothesis that the four underlying factors explained the latent construct PUPP.

The total proportion of variance in PUPP explained by the four factors was about $60 \%$, and that shows a relatively high number of variances explained by items in these four factors after the PAF analysis. The relatively good reliability of the four factors $(\alpha=0.68-0.97)$ suggests that these four scales can be used as empirical measures for further analysis of public perceptions related to UAS. However, the relatively fair reliability of the Knowledge scale $(\alpha=0.68)$ may require further analyses and re-validation to improve the reliability.

The model also suggests that the exogenous variables with the most and least significant impacts on PUPP were Safety Risk-Benefit and Functional Knowledge, respectively. As UAS technology is emergent, it may not be surprising 
that public knowledge is relatively minimal; this seems to play an essential role in shaping user perception on utilization. The observed minimal Functional Knowledge base also implicitly affect the other three factors because Knowledge rests on inference and exposure. This highlights the importance of information in shaping user perceptions.

It was interesting that about $64.5 \%$ of respondents were partially knowledgeable about UAS while $27.4 \%$ were not knowledgeable. The net effect is that there is relatively inadequate knowledge about the technical, legal and economic parameters of UAS integration into the NAS and possible utilization for commercial purposes by respondents. The minimal knowledge about a phenomenon may have a binary effect. On the one hand, it could build up enthusiasm and a more profound quest to probe and understand. On the other hand, it could generate fear and aversion as implied by Shi, Siegrist, and Arvai (2016) in their recent research which argued that knowledge is a driver of cognitive perception of phenomena.

About $85.5 \%$ of respondents had their information on UAS from electronic news media, and only a tiny percentage $(0.3 \%)$ received their knowledge through formal educational outlets. The results suggest that even though the FAA, academia and industry partners may be advocating for UAS and doing some work in trying to provide much information on UAS, it may not be trickling down effectively as only $0.8 \%$ of respondents had any information on UAS from FAA outfits.

Other sources such as aviation recreational clubs and trade organizations contributed about $1.2 \%$ to the knowledge-base of respondents. The results may be suggestive of significant knowledge on UAS gained through the electronic news media which may not always reflect true and empirically-sound perspectives on UAS integration and utilization compared to formal sources such as academia, industry partners and regulatory bodies such as the FAA.

It is therefore imperative from a theoretical viewpoint and policy stance that massive financial and material resources couple with educational investment be made in ramping up quality information on UAS via electronic news media and channels on the social, economic and technical benefits of UAS integration into the nation's transportation system. The knowledge gap needs to be reduced, and both formal and informal approaches should be adopted to do this.

Formal approaches may include curricula modifications from basic educational levels up to the undergraduate level by introducing UAS technology studies early, particularly in the Science, Technology, and Mathematics (STEM) 
fields. This could include interdisciplinary research and the development of the knowledge base regarding UAS from technical, safety, psycho-social, economic and human-factor perspectives.

At the informal level, the creation of UAS recreational and hobby clubs established through local flying clubs and industry organizations such as Aircraft Owners and Pilots Association. These organizations can arrange for subject-matter experts to provide educational seminars and guidance materials on technical, legal, social and economic benefits and implications of UAS integration into the NAS. The FAA and other partners in academia can use social media and other web-based resources to facilitate extensive educational drive and building of requisite UAS knowledge among the public.

Research on UAS and other interesting industry findings can be distilled into a format that will appeal to the public. Examples include documentaries on the fabrication, principles of operations, legal requirements for use and the safety -risk implications of using UAS in the NAS. This can help dispel popular myths and misconceptions and therefore reduce any fear or aversion toward commercial UAS utilization.

Such knowledge may also create the capital for the public to make responsible safety-risk benefit analysis and decisions in UAS use for both recreational and commercial activities. Without such an orchestrated knowledge drive, it may be difficult to break barriers of unfamiliarity that catalyze aversion to UAS use in commercial air transportation.

It is reasonable to surmise that the bedrock of the other three PUPP factors is Knowledge about UAS. It was therefore counter-intuitive that the measured construct Functional Knowledge was negatively related to PUPP albeit with a marginal regression coefficient. A possible reason could be that the respondents' awareness of their minimal functional knowledge creates a curious desire to use UAS for commercial travel and to satisfy their primal curiosity of the technology. The marginal regression weights suggested further and enhanced refinement of construct items and re-validation using similar sample sizes.

The correlation between Safety-Risk Benefit and Utilization Trust was positively high and makes logical and empirical sense. The results suggest that respondents weighed the safety and risk benefits of using UAS and if the net effect was positive were more likely to trust any use for commercial services. This finding corroborates earlier research that emphasizes that trust has always been a central issue in philosophical and ethical approaches to evaluating the technology. 
This is also in line with suggestions in extant research that major trust concerns of technology range from issues of safety and reliability to analyses of risk and development of precautionary standards (Kiran \& Verbeek, 2010). Also, the safety-risk analysis in using any technology implies trusting oneself to that technology (Kiran \& Verbeek, 2010) and involves factors such as reliability, validity, utility, robustness, and false-alarm (Hoffman, Johnson, Bradshaw, \& Underbrink, 2013).

The correlation between Safety-Risk Benefit and Operational Integration Support was positively statistically significant, even though the strength of relation was weak. This finding is in tandem with recent findings by Reddy and DeLaurentis ( 2016) who also observed that support for UAS is conditional and complex with determining factors being risks, application, environment, and benefits of UAS operations and applications.

This research and the findings of Reddy and DeLaurentis (2016) research suggest that the general populace and stakeholder groups show strong support for public service, land management, and earth science applications of UAS but a different approval for applications such as homeland security and commercial operations.

Regarding the variations in responses of demography, it was interesting to note that there were statistically significant differences in the mean scores on Safety-Risk Benefit for males and females, with males having a relatively higher score. The results corroborate findings in a meta-analysis of 150 studies on gender and safety-risk benefit by Hitchcock (2011) that suggest that perceptions on risk and safety-benefits in technology variables are implicitly affected by gender if underlying sub-variables such as culture and cross-national effects are controlled for.

Hitchcock reflects on the "Safety Concerns Hypothesis," which states that health and safety are more salient to women compared to men. This difference is reflected in higher levels of UAS safety concern among women compared to men. The hypothesis also asserts that women's concerns are associated more with the consequences and personal costs compared to men's concerns.

The results also corroborate earlier findings by Arch (1993) who suggests that safety-risk benefit perceptions between the genders can be influenced by the fact that sectors of society that benefit less from risky technology and have less power and control may be less motivated to participate in the presence of risk. 
The implications are that females who are societally perceived to wield less power and control are likely to strive to reduce risk and to underrate their ability to respond to risks. This assertion by Arch may be supportive of the suggestion that females tend to exhibit more alacrity to fly as passengers in commercial UAS compared to males who may be apter to see "challenge" in risky and novel situations and to overrate their ability to cope.

There was a statistically significant difference between the mean scores of G.E.D. holders and B.S. groups on items related to Functional Knowledge with the G.E.D. holders appearing to be more knowledgeable about UAS compared to B.S. holders. This result seemed somewhat counter-intuitive as one would expect college -level respondents to have greater exposure to more sources of information, and therefore higher levels of UAS knowledge compared to G.E.D. holders.

A plausible explanation may be the heightened interest and vocational nature in the use of UAS (especially small UAS) by the rather large number of amateur enthusiasts in the US, some of whom may not necessarily be college graduates but do enjoy reading and gaining extensive knowledge about technology related to their "hobby."

Another reason for the relatively higher knowledge of UAS by G.E.D. holders may be related to the level of safety-risk benefits of UAS utilization. Hitchcock (2011) suggests that "machismo" socialization may be at play among less highly educated people that increases their enthusiasm in skill-based activities that inherently entails higher risk, while the economic and political advantages of people with higher levels of education may contribute to that subgroup's "neutralization" of risk.

Some G.E.D holders who are vocational and technically oriented see novel opportunities in emerging technology such as UAS. For these G.E.D holders to build their human-capacity and improve their socio-economic status, they may exhibit great motivation to delve deep for UAS information through more informal sources such personal blogs, info shares, community webinars and personal websites to search for both training and employment opportunities.

It was also surprising that both crew and business class passengers seem to be more likely to trust and travel commercially by UAS compared to others. With the threat of possible job loss for aircrew if UAS commercial operations become a reality in the future, it was quite interesting that aircrew indicated greater 
willingness to travel by UAS and not have some level of distrust based on economic reasons.

An explanation could be that their level of training and systems knowledge on UAS tends to make aircrew members have lower apprehension and safety concerns compared to non-crew respondents. Further, aircrew members may be having greater understanding of the safety systems and redundancies that are typically built into air transportation systems to make them safe for commercial operations.

It is expected that there will invariably exist the possibility of that pilotless commercial UAS will have human cabin crew or surface-based operators to serve as operational redundancies, so that public concerns over air safety (and aircrew anxiety regarding job loss) may be allayed. Regarding non-crew members, it is anticipated that a subset of these, business travelers, will be motivated to travel by UAS so they can benefit from travel ease and convenience that will facilitate their business transactions.

In a contemporary era of digital media and internet-based information dissemination, it was not surprising that none of the PUPP factors was significant per geographical location. In a global environment with quick and easy access to information, learning and forming opinions on emergent phenomena can easily be shaped by the media and public. Thus, the physical location may not be an effective barrier to perception-influencing information.

\section{Limitations and Suggestions for Future Research}

As with any correlational or predictive research that attempts to model social perception based on a sample, this research does not attribute cause-effect and results should be generalized to the entire population without consideration some confounding variables such as the effects of environmental and socio-cultural factors on public perceptions. Also, safety occurrences, legal and political discourse shaped by the media on rights, confidentiality issues on the use of UAS may invariably affect or bias the responses.

The use of the Mechanical Turk with the cash incentive-based approach could bias the responses of respondents even though every effort was made to restrict multiple responses. The research was restricted to respondents over 18 years of age, but it was difficult to validate physically or real-time compliance since it was web-based administration and it was assumed that all respondents were truthful about their age and backgrounds. 
Researchers in this study envisage that future research will focus on refining the PUPP factors and include respondents from a more varied set of backgrounds, to enhance the efficacy and robustness of the measurement model. Future studies will also focus on PUPP application on an international sample. Other research areas include the use of the PUPP survey instrument to assess the perceptions of different classes of UAS users (for example professional users and recreational users) to determine the differences in their safety-risk perceptions and support for regulatory policies regarding UAS integration into the US airspace.

\section{Conclusion}

Existing literature provides evidence of mixed public perceptions of unmanned aerial technology, and such complexity of public support for or opposition is exacerbated by the multiple applications of UAS. Specifically, regarding integration of UAS into the national airspace, public concerns include privacy infringements, impact on national security and the economy, and risks of damage to property and people.

These concerns influence public perceptions regarding the acceptance or otherwise of UAS technology. For this reason, identifying the factors that influence public perceptions of UAS and assessing the relationships between these factors are expected to help equip industrial UAS stakeholders, technology engineers, government agencies and regulatory institutions to successfully integrate UAS into the NAS.

In a bid to contribute to the literature on this issue, this paper established four underlying measured constructs to encapsulate the backgrounds and concerns of UAS stakeholders: functional knowledge, utilization trust, operational integration support, and safety risk-benefits. The results of the paper showed that these constructs could serve as adequate underlying measures upon which the overall opinion of the stakeholders can be assessed using a novel instrument termed the Public Utilization Perception Potential (PUPP).

The PUPP was validated using Principal Axis Factoring, Cronbach's Reliability test. A measurement model is hypothesizing the relationship between the underlying constructs and PUPP was further assessed using Structural Equation Model (SEM) and determined to be a good fit of data using established goodnessof-fit indices criteria. The paper recommends that investments in informational resources, training and support for advocacy groups by government, industry, and academia will enhance public knowledge and perceptions on the immense benefits 
of UAS technology in all facets of human activities such as transportation, law enforcement, emergency response and disaster management. 


\section{References}

Arch, E. C. (1993) Risk-taking: A motivational basis for sex differences. Psychological Bulletin, 73(3), 9. doi: https://doi.org/10.2466/pr0.1993.73.1.3

Brown, T. A. (2006). Confirmatory factor analysis for applied research. New York, NY, USA: Guilford.

Clothier, R. A., Greer, D. A., Greer, D. G., \& Mehta, A. M. (2015). Risk perception and the public acceptance of drones. Risk Analysis, 35. doi: https://doi.org/10.1111/risa.12330

Dalamagkidis, K., Valavanis, K., \& Piegl, L. (2012). On integrating Unmanned Aircraft Systems into the National Airspace System. Dordrecht, Netherlands: Springer.

Elwell, D. (2017). FAA News: Drone integration. Federal Aviation Administration, Retrieved from https://www.faa.gov/news/speeches/news_story.cfm?newsid=22294

FAA. (2012). Federal Aviation Administration. Retrieved from https://www.faa.gov/uas/media/Sec_331_336_UAS.pdf

FAA. (2016). Operation and certification of Small Unmanned Aircraft. Washington, D.C., USA: Department of Transportation

Field, A. (2013). Discovering statistics using SPSS (4 ${ }^{\text {th }}$ ed.). London, UK: Sage Publications, Ltd.

Harman, G. (1990). Skepticism and the definition of knowledge. London, UK: Routledge.

Hitchcock, J. L. (2001). Gender differences in risk perception: Broadening the context. Risk, 12(4), 179. Retrieved from http://scholars.unh.edu/risk/vol12/iss3/4

Hoffman, R. R., Johnson, M., Bradshaw, J. M., \& Underbrink, A. (2013). Trust in automation. IEEE Intelligent Systems, 28(1), 84-88. 
Hu, L.-T., \& Bentler, P. M. (1999). Cutoff criteria for fit indexes in covariance structure analysis: Conventional criteria versus new alternatives. Structural Equation Modeling, 6, 1-55.

IBM SPSS (2015). IBM SPSS Amos. Retrieved from http://www.spss.com.hk/amos/

Kasperson, R. E., Kates, R. W., \& Hohenemser, C. (1985). Hazard management. Boulder, CO, USA: Westview Press.

Kates, R., Hohenemser, C., \& Kasperson, J. (1985). Perilous progress: Managing the hazards of technology. Boulder, Colarado, USA: Westview Press.

Kiran, A. H., \& Verbeek, P. P. (2010). Trusting ourselves to technology. Knowledge, Technology \& Policy, 23(3-4), 409-427.

Kline, R. B. (2005). Principles and practice of structural equation modeling. New York, NY, USA: The Guilford Press.

McKnight, H., \& Chervervany, N. (1996). The meaning of trust. Minneapolis, MN, USA: University of Minnesota.

Mehta, R., Rice, S., Winter, S., Moore, J., \& Oyman, K. (2016). Public perceptions of privacy toward the usage of Unmanned Aerial Systems: A valid and reliable instrument. Human Factors and Applied Psychology Conference 2015.

Reddy, L., \& DeLaurentis, D. (2016). Opinion survey to reduce uncertainty in public and stakeholder perception of unmanned aircraft . Journal of the Transportation Research Board, 26000, 80-93.

Renn, O. (2008). Risk governance:Coping with uncertainty in a complex world. London, UK: Sprinter science+ Business Media B.V.

Renn, O., \& Benighaus, C. (2013). Perception of technological risk: insights from research and lessons for risk communication and management. Journal of Risk Research, 16(3-4), 293-313.

RTI. (2016). Research Triangle Institute International. Retrieved from http://www.rti.org/publications/abstract.cfm?pubid=21155 
Scheer, D., Gold, S., Benighaus, C., Benighaus, L., Ortleb, J., \& Renn, O. (2010). Communication of Risk and hazard from the angle of different stakeholders. German Federal Institute for Risk Assessment, BfR Wissenschaft. Berlin, Germany: BfR Wissenschaft.

Shi, J., Siegrist, V. H., \& Arvai, J. (2016, April 25). knowledge as a driver of public perceptions and about climate change reassessed. Nature climate Change, NCLIMATE2997. doi: 10.1038

Slovic, P. (1992). Perception of risk reflections on the psychometric paradigm. In S. Krimsky, \& D. Golding, Social theories of risk. Santa Barbara, CA, USA: Praeger.

Stevens, J. (2002). Applied multivariate statistics for the social science (4 ${ }^{\text {th }} \mathrm{ed}$.). Hillsdale, NJ, USA: Erlbaum.

Tam, A. (2011). Public perception of unnmanned aerial vehicles. West Lafayette, IN, USA: Purdue University Aviation Technology Graduate Student Publications.

Tetrault, C. (2016). Innovative UAV aircraft \& aerial video systems: A short history of $U A V s$. Retrieved from http://www.draganfly.com/news/2009/03/04/a-short-history-of-unmannedaerial-vehicles-uavs/

Weibel, R., \& Hansman, J. (2004). Safety considerations for operation of different classes of UAVs in the NAS. Chicago, IL, USA: American Institute of Aeronautics and Astronautics. 


\section{Appendix}

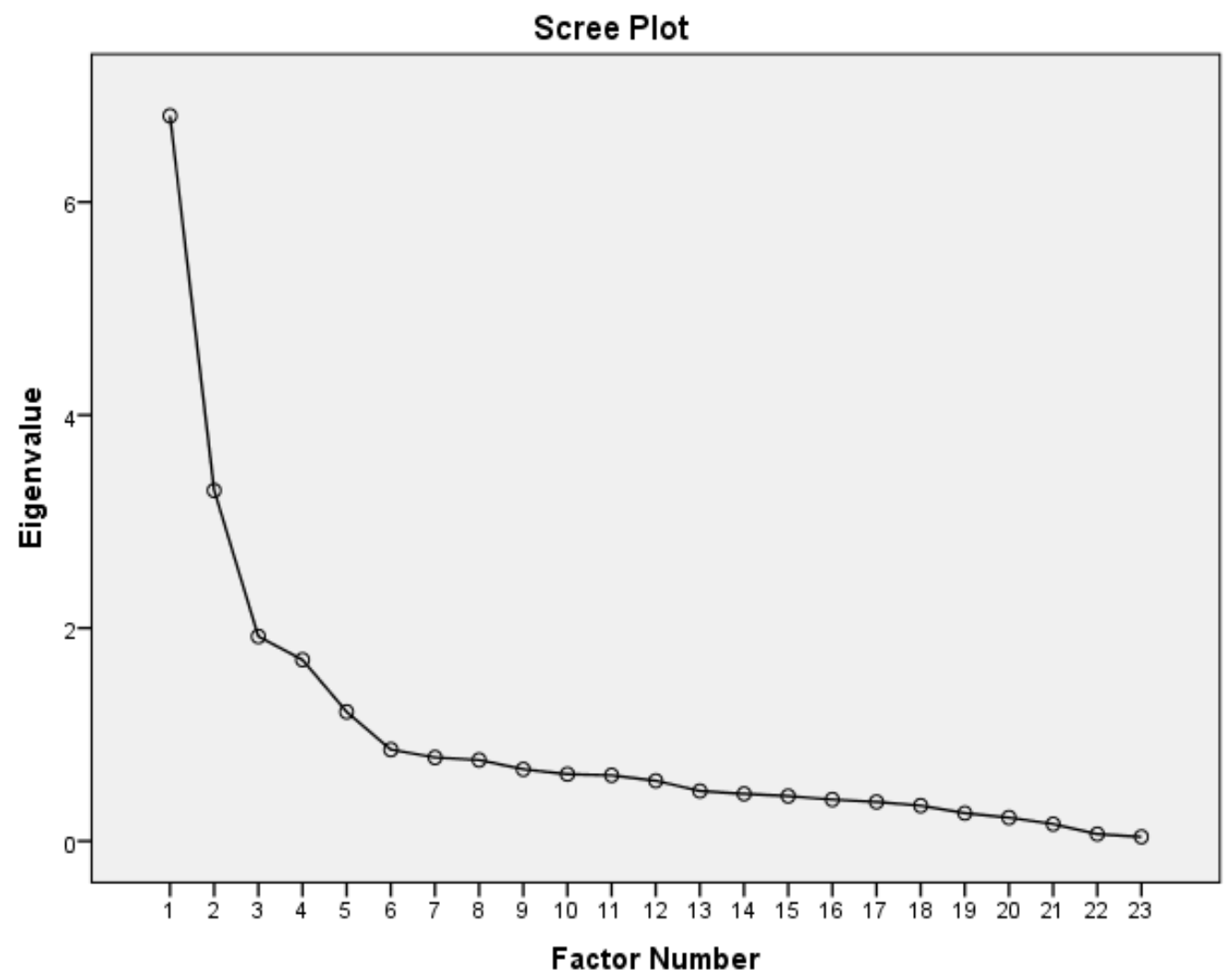

Figure 1A. Scree Plot of Extraction of factors based on Eigenvalue and Point of Inflexion. 